\title{
O BRASIL E O FMI: UMA ANÁLISE NAS CARTAS DE INTENÇÃO DE 1998 A 2004 E O CONSTANTE PROBLEMA DA INFLAÇÃO
}

\author{
BRAZIL AND THE IMF: AN ANALYSIS IN THE LETTERS OF INTENT FROM \\ 1998 TO 2004 AND THEC ONSTANT PROBLEM OF INFLATION
}

\author{
Milene Fádua Vieira dos Santos ${ }^{1}$ \\ http://orcid.org/0000-0002-8537-4102 \\ http://lattes.cnpq.br/8737374754575668
}

\section{Ludmylla Monteiro Mendes dos Santos ${ }^{2}$}

Recebido em 29 de junho de 2019

Aceito em 14 de dezembro de 2019

RESUMO:O presente artigo tem por objetivo principal analisar a relação histórica construída entre o Brasil e o Fundo Monetário Internacional (FMI),considerando os períodos de 1998 a 2004 — último ano de empréstimo concedidos ao país.Além disso, o artigo também analisou a importância da criação do Real para a economia brasileira, uma vez que as moedas anteriores não cooperaram para a redução da inflação. Para chegar a um resultado satisfatório, foram pesquisados diferentes documentos que configuram um debate acerca do objeto proposto. Por meio das pesquisas pode-se perceber que os empréstimos foram de extrema necessidade para ajudar o Brasil a ter um melhor desenvolvimento econômico, entretanto, não foram o suficiente para sanar o problema inflacionário. Foi perceptivo também que a criação do Real levou a economia brasileira a um novo patamar, porém não alcançou as expectativas desejadas pelo governo da época. Dito isso, essa pesquisa se mostra mais quantitativa que qualitativa,uma vez que traz dados que justificam os fenômenos descritos ao longo do texto.

Palavras-chave: Brasil. Fundo Monetário Internacional. Plano Real. Economia brasileira.

\begin{abstract}
The main objective of this article is to analyze the historical relationship built between Brazil and the International Monetary Fund (IMF), considering the periods from 1998 to 2004 the last year of loan granted to the country. In addition, the article also analyzed the importance of creating the Real for the Brazilian economy, since the previous currencies did not cooperate to reduce inflation. To reach a satisfactory result, different documents were searched that constitute a debate about the proposed object. Through research, it can be realized that loans were extremely necessary to help Brazil have better economic development, however, they were not enough to remedy the inflationary problem. It was also perceptive that the creation of the Real took the Brazilian economy to a new level but did not reach the expectations desired by the government of the time. That said, this research is more quantitative than qualitative, since it brings data that justify the phenomenon described throughout the text.
\end{abstract}

Keywords: Brazil. International Monetary Fund. Real Plan. Brazilian economy.

${ }^{1}$ Graduada em Relações Internacionais pelo Centro Universitário de Belo Horizonte (UNIBH). E-mail: milenefadua@gmail.com

${ }^{2}$ Graduada em Relações Internacionais pelo Centro Universitário de Belo Horizonte (UNIBH). E-mail: luddymmendes@gmail.com 


\section{INTRODUÇÃO}

O Fundo Monetário Internacional(FMI) é uma organização que mantém relações com 189 Estados e, sua criação se dá em 1945 - mesmo ano da criação da Organização das Nações Unidas (ONU). O Brasil já dialogava com o FMI no final dos anos 50, porém um dos acordos mais importantes foi rompido pelo governo de Kubitschek, no qual o presidente começou a depreciar o Fundo, acreditando na independência financeira do país sem necessariamente precisar de ajuda externa. Por mais que o país tentasse resolver seus problemas econômicos sem ajuda de terceiros, não tardou entrar em diversas crises. Uma das principais crises foi o estrangulamento externo3, que configurou no planejamento de ideias para equilibrar a balança comercial.4

Para tentar combater as consequências das crises internacionais em sua economia, o país criou uma série de planos para tentar reverter o déficit. É neste contexto que vão nascer os planos Cruzado, Cruzado II, Plano Bresser, Plano Verão, Plano Collor, Collor II e Plano Real. Aprimor, o Plano Real pareceu ser o que salvaria o Brasil, devido ao seu bom desempenho logo nos primeiros meses ao seu lançamento. Entretanto, por diversos motivos, incluindo a desvalorização da moeda e o constante aumento da inflação, o país se viu obrigado a solicitar ajuda externa do Fundo Monetário Internacional. O diálogo entre o Brasil e o FMI nos anos 50 era uma linha tênue, entretanto, somente em 1998 é que a relação entre as partes se torna mais acentuada. Percebe-se que, ao longo de um bom tempo, o Brasil foi dependente do Fundo.

Com base nas informações apresentadas, optou-se em começar a pesquisa pelo ano de 1998 - mesmo sabendo que as negociações com fundo vinham desde o período da Ditadura Militar, mas especificamente no governo Kubitschek. Entretanto, a escolha deste período se deu pelo motivo da crise cambial ocorrida no ano seguinte, quando houve a desvalorização da moeda nacional. Por esse motivo, o Brasil percebeu que a necessidade de um empréstimo era de extrema urgência para ajudá-lo na reestruturação de sua economia.

Sendo assim, o principal objetivo desse artigo foi analisar a relação históricas entre as partes. Da mesma forma, procurou-se mostrar que os empréstimos valeram ao Brasil em grandes momentos de crise financeira e econômica. Para além disso, identificou-se que o Real foi uma estratégia válida e assertiva, mas não foi unânime para a resolução de todas as dificuldades econômicas sofridas pelo país naquele período.

\section{AFINAL, O QUE É FMI E QUAL SUA FUNÇÃO?}

O Fundo Monetário Internacional (FMI) é uma organização internacional que compõe 189 países, onde seu principal objetivo é promover a cooperação global. Como o próprio nome sugere, a cooperação é para fins econômicos, financeiros e comerciais. O FMI foi criado em 1945, logo após o fim da Segunda Grande Guerra Mundial e seu objetivo primário era a cooperação monetária global, somente em 2012 é que o Fundo passou a tratar de questões macroeconômicas (INTERNATIONAL MONETARY FUND, 2019).

\footnotetext{
${ }^{3}$ Qualquer obstáculo que gere problemas para o crescimento econômico do país. Ex: Má administração, dívidas externas, falta de recursos,entre outros.

${ }^{4}$ Somatória das contas de importação e exportação de um país. Disponível em: <https://www.tororadar.com.br/investi mento/bovespa/balanca-comercial>
} 
O objetivo central do Fundo é assegurar que o sistema monetário se mantenha estável, conseguindo alcançar a eficácia em suas transações. De acordo com o próprio Fundo, existem três maneiras distintas nos quais ele tenta garantir a estabilidade internacional, elas são: acompanhando a economia global junto à economia dos países membros, fornecendo empréstimos a países com dificuldades e dando ajuda aos membros. Por meio disso, compreende-se que o Fundo é responsável por conceder empréstimos a países que passam por más condições financeiras e econômicas, a fim de que esses possam reconstruir suas reservas internacionais. Com o fim do Sistema Bretton Woods ${ }^{5}$, e com o colapso das taxas de câmbio em 1971, o FMI se tornou essencial para ponderar os problemas ocorridos com os choques do petróleo em 1973/74 e 1979 (INTERNATIONAL MONETARY FUND, 2019).

Dessa forma, cabe ressaltar o viés tecnocrata do fundo, uma vez que, dentre o seu sistema de aprovação dos empréstimos aos países membros, é efetuado um estudo das Cartas de Intenção e, também, monitoramento das políticas econômicas regionais presentes em cada Estado. O FMI faz um levantamento técnico e econômico de cada país que envia sua Carta de Intenção, de forma a verificar para quais fins destinam-se o possível valor emprestado. $\mathrm{O}$ nível de desenvolvimento de um país, seu saldo de pagamentos, sua posição de reserva externa e seu nível de todas as dívidas que possui influenciam as decisões de empréstimo (VREELAND, 2007, p. 50).

Os programas do FMI não tratam apenas dos empréstimos, mas também em promover a recuperação econômica, pensando que esta ocorra de forma permanente. Sendo assim, o Fundo exige que um governo reúna condições políticas específicas em troca de um empréstimo em moeda estrangeira. Em retorno ao empréstimo, o FMI exige que os países sigam políticas econômicas para reduzir o consumo interno ${ }^{6}$ VREELAND, 2007, p. 50). É necessário salientar que, os acordos realizados entre FMI e os Estados, nos quais os termos são apresentados, é construído por ambos, sendo assim, os países estão cientes de cada recomendação apresentada pelo Fundo, e podem aceitar ou não o acordo. Para Vreeland (2007, p. 50), os Estados aceitam as políticas econômicas sugeridas pelo FMI, pois necessitam de empréstimo e, no momento, não possuem uma alternativa a não ser aceitar as recomendações, o que não quer dizer que não exista desvio de conduta dos Estados. Lembrando que o FMI recomenda, ou seja,não obriga os Estados, mas espera boa conduta dos mesmos.

\subsection{O BRASIL ANTERIOR AO FMI}

Antes de falarmos de como o Brasil solicitou ajuda ao FMI, é necessário voltarmos um pouco em sua história para entendermos quais foram as circunstâncias que ocasionaram a solicitação de empréstimos. O Brasil, como muitos outros países, sofreu com eventos que abalaram a economia mundial, como os Choques do Petróleo e a Crise da Dívida Externa ${ }^{7}$. Ressaltamos que, o Brasil já dialogava com Fundo desde a Ditadura Militar, mas ao final dos anos 70 até meados de 2000, a situação econômica brasileira exigiu empréstimos internacio-

\footnotetext{
${ }^{5}$ Novo sistema econômico criado em 1944, que tinha por objetivo facilitar o comércio no Sistema Internacional, padronização de taxas cambiais para impedir as depreciações de moedas e construir um sistema financeiro multilateral entre os Estados (o Fundo Monetário Internacional) (GILPIN, 2002, p. 153).

${ }^{6}$ Configura-se na soma dos bens de consumo interno, ou seja, gastos que foram realizados somente em território nacional.

${ }^{7}$ Crise que se iniciou em 1979, nos EUA. A fim de assegurar a economia, o Banco Central Americano eleva a taxa de juros, devido aos problemas ocasionados com os Choques do Petróleo.
} 
nais com uma frequência maior.

Devido a esses eventos, a economia global ficou fortemente abalada e muitos países não tiveram condições de efetuar os pagamentos externos em dia, uma vez que os processos inflacionários estavam disparados. A economia latino-americana sofreu bastante com esse fenômeno, tornando as esperanças de quitação das dívidas quase utópicas naquela situação. $\mathrm{O}$ Brasil, como os demais países da América Latina, se viu afundado em dívidas e com isso precisou traçar um plano que pudesse ajudar no resgate de sua economia.

Para impedir que sua economia continuasse a sofrer, o Brasil adotou uma série de planos econômicos para sua estabilização, sendo esses: O Plano Cruzado, Cruzado II, Plano Bresser, Plano Verão, Plano Collor, Collor II e Plano Real. Todos esses planos foram fracassados, exceto o Plano Real — no qual falaremos mais especificamente no tópico a seguir. Ao ponto em que eram implementados, ficava claro que os planos continham diversos erros de planejamento e a inflação continuava sendo um problema para a economia brasileira.

Todos os planos até aquele momento passavam por processos heterodoxos ${ }^{8}$, tornando de difícil acesso a eficácia da economia brasileira. Até que regulamentasse o Plano Real, o país se viu falhando em todos os planos, tornando a economia brasileira a cada dia mais insustentável. Além de ter que lidar com os problemas econômicos, o Brasil ainda teve que lidar com alguns escândalos que assombravam seu território, como por exemplo, a queda do Governo Collor e os diversos casos de corrupção.

Depois de inúmeras tentativas, o Brasil enfim conseguiu pôr em prática um plano que o ajudaria a sair dos inúmeros problemas econômicos e financeiros. Porém, vale lembrar que, isso não o levou a sair completamente da crise, mas o colocou de volta nos eixos, dando-lhe um norte para futuras resoluções.

\subsubsection{O Plano Real}

Antes que o Real se tornasse a moeda que ajudaria o Brasil a sair da lama em que se encontrava, criou-se a Unidade Real de Valor (URV) ${ }^{9}$, que previa finalizar os ajustes fora de sincronia, seja sobre preços ou salários. O URV propunha uma padronização sobre os índices de reajuste, tornando possível a sincronicidade diária da moeda que seria criada futuramente (CÔRREA, 2014). O Plano Real foi executado em fases diferentes, sendo estas essenciais para concluir a moeda final. Foram três fases até que a moeda tomasse forma, essas fases foram: o ajustamento fiscal, a desindexação e a euforia do consumo e âncora nominal. Esses três processos levaram a uma série de medidas,nos quais o Real seria a moeda que ajudaria ao Brasil no seu sistema inflacionário e melhoraria o poder de compra da população. $\mathrm{O}$ resultado do início do processo pode ser visto logo no primeiro semestre de 1994, no qual a inflação de $780 \%$ foi para 45\% ao mês durante a passagem da URV e, em seguida, passou a $18 \%$ no segundo semestre e 35\% nos 12 meses que sucederam o lançamento do Real (CÔRREA, 2014).

\footnotetext{
${ }^{8}$ De acordo com Bentub (2014), engloba-se a esta teoria, principalmente, os keynesianos e pós keynesianos. Os heterodoxos destacam o papel do Estado, como agente regulador é capaz de promover o crescimento econômico. A ideia principal desta teoria é que, o sistema não tende de forma automática ao pleno emprego dos recursos, isto é, o pleno emprego é uma possibilidade.

${ }^{9}$ Fatores de Atualização Monetária e Taxas de Juros Referências.
} 


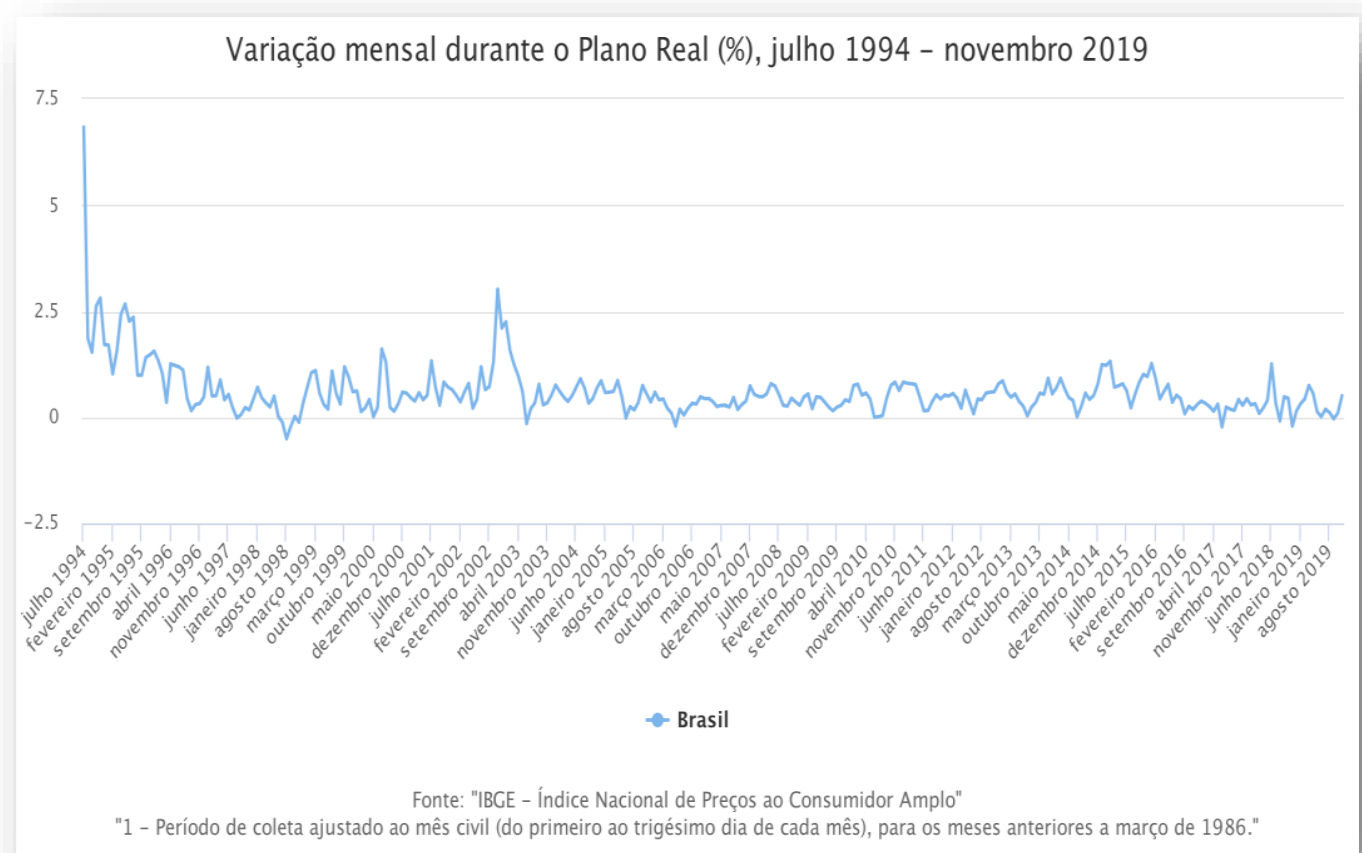

Através do gráfico percebe-se que a implementação do Real foi bastante eficaz para ajudar ao Brasil em seu processo inflacionário. Mesmo que o ajuste fiscal não tenha sido eficaz como esperado, a transição do URV foi essencial para dar apoio para outros estágios. A nova moeda foi de suma importância, mas não garantiu sua estabilidade total. A economia conseguiu ter um crescimento bom com a nova implementação, uma vez que houve demanda dos mercados internacionais.

Devido as dívidas externas, o protecionismo, juros altos, a economia mundial começou a desacelerar. Crises como a do México, em seguida a Crise Asiática, onde a Bolsa de Hong Kong teve impacto expresso na economia dos Tigres Asiáticos ${ }^{10}$. Em seguida, em 1998, houve a Crise na Rússia, onde a comunicação de moratórias provocou especulações e instabilidade nas bolsas e no mercado internacional. Todos esses eventos levaram ao Brasil a tomar partido para controlar o câmbio e evitar novamente um possível cenário inflacionário. Foram feitas reservas de taxas de câmbio, âncora de juros e ajustes fiscais que acabaram sendo ineficazes. Com dificuldades para honrar seus compromissos, o país se viu sujeito a tentar um acordo com o FMI, onde essa relação será melhor tratada no tópico seguinte.

\subsection{AS CARTAS DE INTENÇÃO AO FMI}

Conforme levantado no tópico anterior, a situação financeira do Brasil não estava estável. As crises internacionais contribuíram para o déficit na economia brasileira, tornando a situação mais caótica. No contexto da crise russa, o Brasil apresentou uma drástica queda em sua reserva econômica, de aproximadamente 72 bilhões no período anterior à crise para 40 bilhões em meados de novembro de 1998, quando a crise já havia atingido México e a Ásia

${ }^{10}$ Informações sobre a Crise Asiática, ver em: < https://www.ebah.com.br/content/ABAAAADegAB/a-crise-asiatica?
part $=6>$

PRACS: Revista Eletrônica de Humanidades do Curso de Ciências Sociais da UNIFAP https://periodicos.unifap.br/index.php/pracs ISSN 1984-4352 Macapá, v. 12, n. 3, p. 65-73, dez. 2019 
(ALMEIDA, 2003, p. 13), dando ênfase a necessidade da realização do acordo junto ao Fundo.

Diante da crise financeira externa e interna e, uma eminente crise cambial, o Brasil não viu outra solução para o enfrentamento de sua crise se não os empréstimos fornecidos pelo Fundo. Sendo assim, em 1998, após a reeleição de Fernando Henrique Cardoso, foi assinado o acordo stand-by ${ }^{11}$ com o FMI, no valor de 18 bilhões de dólares, com um prazo vigente de 36 meses, no qual destacavam-se rígidas regras de comprometimento fiscal, monetário e econômico, como, por exemplo, a Lei de Responsabilidade Fiscal, sendo esta importante para o controle de gastos públicos, um dos grandes motivos do aumento das dívidas do país (MELO, 2006, p, 13).

Em 1998, ano de assinatura do acordo com o Fundo, o país já apresentava, em doze meses, um déficit que já atingia 34 bilhões de dólares, ou seja, 4,43\% do PIB, apresentando assim, a necessidade de uma contribuição suplementar de recursos institucionais, adicionalmente ao volume de investimentos diretos e de subsídios por motivo de privatizações (que em 1998 atingiram, de forma conjunta, um volume recorde de 24,5 bilhões de dólares) (MELO, 2006, p, 13).

A primeira carta de intenção disponibilizada pelo FMI em seu site, com relação ao Brasil, é de 13 de novembro de 1998. Na carta, Brasil descreve as políticas que o país adotaria com os recursos. Anterior a1998, o Brasil dialogou diversas vezes com o FMI até que os acordos fossem concretizados.

Nesta carta, o Brasil declarou que o Plano Real foi primordial para que gastos federais, a modernização do sistema tributário e para a disciplina fiscal em nível estadual, entretanto, o setor público não financeiro (NFPS) ${ }^{12}$ permanecia como fonte de preocupação. A instabilidade de preço, a desvalorização do setor público exigiu recursos da poupança externa, o que ocasionou um déficit em conta corrente da balança de pagamento de menos de 0,5 do PIB em 1994.

Em meados de 1998, a dívida externa bruta do Brasil estava em cerca de 228 bilhões de dólares (acima de 28\% do PIB). No início de 1999, foi anunciado um montante de 18 bilhões de dólares com o FMI, onde o Brasil se comprometeu em seguir à risca as demandas feitas pelo Fundo. Em 1999, o Brasil passou por uma crise cambial (ARANTES, 2002, p. 132 apud MELO, 2006, p. 120), que foi ocasionada pela desvalorização do Real. A desvalorização da moeda ocorreu no início de 1999, já o memorando do Brasil ao FMI ocorre em julho do mesmo ano.

Segundo o memorando, o Brasil teve um desempenho melhor do que era esperado no primeiro semestre de 1999. O PIB e o desempenho da inflação tiveram bom desenvolvimento, mas a balança de pagamento ainda era uma incerteza constante. Foi primordial a ajuda do FMI no início de 1999, mas a desvalorização da moeda acabou acarretando problemas, nos quais buscou-se uma política cambial mais flexível. Mesmo assim, segundo as informações do Memorando, as expectativas para 1999 eram positivas (INTERNATIONAL MONETARY FUND, 1999).

No ano 2000, o Brasil apresentou duas Cartas ao FMI-naquele ano o país apresentou

11 Para melhores informações: <https://www.imf.org/external/lang/portuguese/np/exr/facts/sbap.pdf>

12 Empresas públicas federais, estaduais e municipais, com exceção dos bancos, distribuidores de títulos, corretores e outras companhias com licença para atuação no mercado. Em suma, é a reunião das principais estatais, exceto as instituições financeiras. 
uma melhora considerável no que diz respeito ao valor de sua dívida externa e interna, assim como a diminuição no problema inflacionário. Cabe ressaltar que, no primeiro trimestre de 2000, o Brasil conseguiu quitar metade do empréstimo fornecido pelo FMI (em torno 10 bilhões de dólares).

A primeira carta do ano é datada de 20 de abril de 2000, seu foco e perspectiva para o ano girava em torno da manutenção do ajuste fiscal, a diminuição de juros e a redução da inflação, uma vez que o controle dos fatores citados impulsionaria uma melhora em diversos setores levantados no memorando: a recuperação da produção e o declínio do desemprego; reforçar ainda mais as contas externas; e continuar o processo de modernização e integração da economia brasileira na economia global, por meio de reformas estruturais, privatização e promoção da concorrência (INTERNATIONAL MONETARY FUND, 2000). Para além disso, o crescimento do PIB configurou novamente em mais uma carta, desta vez com o propósito de alcançar no ano 2000 um crescimento de 4\%.

A segunda carta deste ano, em 3 de novembro, o Brasil apresentou melhoras na economia do país, citando todas as metas apresentadas na primeira carta — que haviam sido cumpridas parcialmente. No segundo trimestre de 2000, a economia brasileira apresentou, pela primeira vez, uma estabilização(INTERNATIONAL MONETARY FUND, 2000). O PIB brasileiro cresceu em média 3,6\% no primeiro trimestre do ano, em comparação com o mesmo período do ano de 1999, refletindo uma taxa de crescimento anualizada ajustada sazonalmente de 4,8\% em comparação com o segundo semestre de 1999 (INTERNATIONAL MONETARY FUND, 2000). Para além do crescimento do PIB, o Brasil apresentou aumento de empregos - que era uma das metas apresentadas na primeira carta enviada ao Fundo, em 2000.

Para o governo brasileiro, uma das preocupações recorrentes era a diminuição da inflação com o passar dos anos, fato alcançado em 2000. A taxa de aumento de 12 meses no IPCA caiu de 8,9\% em dezembro de 1999 para 6,5\% em junho de 2000- significativamente abaixo da meta central de 7,0\% para aquele mês no programa -, aumentada em julho-agosto, mas desacelerou novamente para 7,7 por cento em setembro, 0,2 pontos percentuais acima do limite superior da faixa interna do programa (INTERNATIONAL MONETARY FUND, 2000). Sendo assim, com a diminuição da inflação e o aumento de empregos e do PIB, assim como o pagamento parcial do empréstimo realizado em 1998, o país conseguiu diminuir para 232 bilhões de dólares (40,8\% do PIB estimado) em agosto de 2000, de cerca de 241 bilhões de dólares (45,6\% do PIB) no final de 1999 (INTERNATIONAL MONETARY FUND, 2000).

Dessa forma, entende-se que o ano de 2000 demonstrou uma recuperação econômica e, para além disso, o cumprimento de metas levantadas tanto na Carta de 1999 como na Carta do primeiro trimestre de 2000. Cabe ressaltar que, a Lei de Responsabilidade Fiscal foi mantida, sendo essencial para um progresso significativo nas reformas fiscais pensadas pelo governo brasileiro.

Em 2001, o Brasil solicitou ao FMI, por um período de 15 meses, 15.650 milhões de dólares. Ao solicitar esse novo stand-by, o país pediu cancelamento do acordo aprovado em dezembro de 1998, no qual expiraria no final de 2001. Mesmo a ajuda contínua do Fundo, o Brasil no início de 2001 sofria com choques externos e internos, principalmente com uma crise energética interna. Por esse motivo, o governo brasileiro precisou tomar uma série de medidas para lidar com as questões monetárias, principalmente com as consequências infla- 
cionárias. O governo acabou por criar um pacote de medidas para aceleramento dos investimentos no setor energético, por isso foi feito um novo acordo com o Fundo (INTERNATIONAL MONETARY FUND, 2001).

Em 2002, o Brasil escreveu um memorando ao FMI, neste memorando o país informou que a inflação foi maior do que o esperado, no qual atingiu 7,7\% do limite superior de 6\% estabelecido no acordo stand-by. O Brasil manteve diálogo constante com o FMI, declarando todas as suas políticas implementadas desde o novo acordo firmado em 2001. Todo o tempo é possível ver nas Cartas a constante pauta sobre a inflação e o PIB, nos quais o país teve altos e baixos desde o lançamento do Real e das crises internacionais. Para poder atingir um superávit primário satisfatório, o país informou que elevaria de 3,5\% do PIB para 3,75\% naquele ano. Naquele momento, o governo desejou recomprar a dívida externa, nos quais venceriam em 2003 e 2004 por um valor aproximado de 3 bilhões de dólares. O objetivo era sacar os recursos do Fundo que estariam disponíveis após a terceira revisão do acordo. O critério era o piso de reservas internacionais líquidas, nos quais se reduziria de 20 bilhões de dólares para 15 bilhões, os quais facilitaria a recompra da dívida externa (INTERNATIONAL MONETARY FUND, 2002).

No ano de 2003, primeiro ano de Governo Lula, o Brasil enviou um total de 4 Cartas ao Fundo, sendo que os dois primeiros documentos possuem uma diferença de aproximadamente 3 meses (28 de fevereiro e 28 de maio, respectivamente). O cenário econômico no período não havia melhorado quando comparado ao ano anterior e a incerteza econômica prevalecia no Sistema Internacional. A depreciação do real levou a uma explosão de inflação no final de 2002 que persistiu nos primeiros meses de 2003, com o equivalente a 8,5\% chegando a 9,5 ao final do mesmo ano (INTERNATIONAL MONETARY FUND, 2003).

Embora o PIB nos primeiros meses de 2013tenha apresentado um crescimento de 1,5\% comparado ao ano de 2002, chegando ao equivalente a 2,8\%, não permaneceu a meta de crescimento proposta pelo governo na primeira Carta, sendo assim, ao final do ano o PIB havia crescido apenas $0,6 \%$ se comparado ao mesmo período do ano anterior. $\mathrm{Na}$ última carta do ano de 2003, o Brasil pede ao FMI uma prorrogação do acordo em 15 meses para que fosse possível implantar políticas econômicas e sociais propostas para o ano de 2004, com a promessa de que não seriam feitas mais nenhuma solicitação do tipo.

Em dezembro de 2004,o país estava com a economia fortalecida, no qual conseguiu recuperar 6\% do PIB nos quatro trimestres-um acréscimo de 20\% na mesma época. Em 2003 houve um crescimento de $0,5 \%$, que foi considerado o mais importante, trazendo 1,8 milhão de empregos para o mês de janeiro (INTERNATIONAL MONETARY FUND, 2004). A questão do desempenho do superávit em 2004, foi de 4,5\% no PIB. Esse processo deu uma redução na receita tributária, no qual ajudou na diminuição das dívidas públicas.

Para o ano de 2004, o Brasil apresentou 4 Cartas ao FMI, seguindo o mesmo modelo do ano anterior e, traziam também os resultados e uma prospecção para os três anos seguintes. O panorama geral do que foi alcançado pelo governo brasileiro é disposto na última Carta enviada no ano, em 2 de dezembro de 2004, apresentando novamente as questões ligadas ao PIB e a Inflação, trazendo também como consequência dos dois fatores citados anteriormente, a exportação. Sendo assim, o governo apresentou no documento o crescimento do PIB superior a marca de $6 \%$ dentro do primeiro trimestre do ano. Outro fator comentado foi a inflação, chegando a 5,5\% no primeiro trimestre (INTERNATIONAL MONETARY FUND, 2004).Em 2005, estava prevista uma renovação do acordo entre as partes—o que

PRACS: Revista Eletrônica de Humanidades do Curso de Ciências Sociais da UNIFAP https://periodicos.unifap.br/index.php/pracs ISSN 1984-4352 Macapá, v. 12, n. 3, p. 65-73, dez. 2019 
não ocorreu, resultando posteriormente na quitação da dívida com o fundo em dezembro de 2005. Atualmente, o Brasil tornou-se um dos credores do FMI.

\section{CONCLUSÃO}

Com base nas informações colhidas na pesquisa e nos argumentos apresentados, entendese que o FMI foi de grande importância para o Brasil em períodos distintos de sua economia. Percebe-se que os pontos mais tocados pelo governo nas Cartas de Intenção foram o crescimento do PIB, a inflação e as finanças externas. É notável que em diferentes Cartas, o país apresentou diversas justificativas para concessão dos empréstimos, que em geral foram aplicados no crescimento econômico e na reestruturação das dívidas externas.

Com base nas Cartas de Intenção, nas informações do Banco Central e nas bibliografias apresentadas, é perceptível que os empréstimos concedidos foram de grande valia para o Brasil, dando-o a oportunidade de novamente desenvolver uma economia mais precisa. Ao longo da pesquisa notou-se que os problemas inflacionários estão além, ou seja, mesmo com os empréstimos, o Brasil teve sérios problemas em manter a inflação dentro dos padrões desejados.

O assunto abordado neste trabalho é de extrema importância para diferentes áreas do conhecimento, o que nos leva a compreender os diversos fenômenos que ocorreram na economia brasileira e internacional. Para o futuro, entendemos que é significativo que mais pessoas abordem o tema, a fim de que este se mantenha atualizado e contribua para outras áreas do conhecimento.

\section{REFERÊNCIAS}

ALMEIDA, Paulo Roberto de. O Brasil e o FMI de 1944 a 2002: um relacionamento feito de altos e baixos. Revista História Hoje, São Paulo, n 1, 2003.

BENTUB, Carlos. Economia Ortodoxa versus Economia Heterodoxa.Notas de estudo de Economia, PUC Campinas. 2014.

CÔRREA, Thiago Fontenelle Bossard Cortazio. O Combate à Hiperinflação e a Eficácia do Plano Real. 2014. Monografia (graduação em Economia) Pontifícia Universidade Católica do Rio de Janeiro (PUC RIO) 2014.

INSTITUTO BRASILEIRO DE GEOGRAFIA E ESTATÍSTICA (IBGE). Inflação.Disponível em:<https://www.ibge.gov.br/estatisticas/economicas/precos-e-custos/9256-indice-nacional-deprecos-ao-consumidor-amplo.html?t=series-historicas\&utm_source=landing\&utm_medium=expli ca\&utm_campaign=inflacao\#plano-real-mes $>$

INTERNATIONAL MONETARY FUND (IMF).All Letters of Intent of Brazil. Disponível em: <https://www.imf.org/en/Countries/BRA>

MELO, Andrea Sabbaga de. O Brasil, a Dependência e o Fundo Monetário Internacional: Perspectiva crítica à luz das Cartas de Intenções do governo de Luiz Inácio Lula da Silva. Universidade Federal de Santa Catarina, Florianópolis, 2006.

VRELLAND, James Raymond. The International Monetary Fund: politics of conditional lending. Routledge: Nova York e Canadá, 2007. 